\title{
Charles Larmore: A questão do desacordo Razoável
}

\section{Charles Larmore: The Question of Reasonable Disagree}

\author{
ELNORA GONDIM \\ UNIVERSIDADE FEDERAL DO PIAUÍ
}

Recibido: 22/05/2019 Aceptado:29/07/2020

\section{RESUMEN}

El presente texto trata de la teoría de Charles Larmore, más precisamente, de las relaciones entre las concepciones de desacuerdo razonable, de pluralismo y de liberalismo. Tal teoría tiene como características el intuicionismo racional, contextualismo y defiende una posición realista de la moralidad.

$$
\text { PALABRAS CLAVE }
$$

DESACUERDO RAZONABLE, PLURALISMO, LIBERALISMO, INTUICIONISMO, CONTEXTUALISMO

\section{ABSTRACT}

The present text deals with Charles Larmore's theory, more precisely, of the relations between the conceptions of reasonable disagreement, pluralism and liberalism. Such a theory has as its characteristics rational intuitionism, contextualism and defends a realistic position of morality. KEYWORDS REASONABLE DISAGREEMENT, PLURALISM, LIBERALISM, INTUITIONISM, CONTEXTUALISM 


\section{CONSIDERAÇÕES INICIAIS}

EM TAL TEXTO DISCORREREMOS sobre as ideias propostas por Charles Larmore, filósofo americano contemporâneo, mais precisamente, sobre as relações entre o desacordo razoável, o pluralismo e o liberalismo. Quanto à sua teoria: «É a partir do intuicionismo racional ou, em termos mais precisos, de uma teoria da crença racional com justificações contextualistas, que devemos compreender a teoria política de Larmore» (Fanton, 2015, p. 176). Ele defende uma posição realista da moralidade.

\section{A QUESTÃO DO LIBERALISMO}

Segundo Larmore, para desenvolver uma concepção viável do liberalismo político tem-se que entender a diferença entre o fato do desacordo razoável e do pluralismo. Ele argumenta, explicitamente, que em uma conjuntura de diversidade doutrinária, como a que está presente em muitas sociedades contemporâneas, a razão por si só não pode ser a base para um consenso sobreposto. Para corroborar com isso, Larmore afirma que sua concepção trata dos fundamentos morais subjacentes ao conceito de liberalismo político.

Para tanto, no texto Political Liberalism: Its Motivations and Goals, Charles Larmore assegura que, nos últimos anos, o liberalismo político, entendido como uma forma distinta de teoria liberal e diferente do liberalismo clássico de grandes pensadores como Locke, Kant e Mill, tornou-se uma área vigorosa de reflexão filosófica. Nessa perspectiva, há uma enorme variedade de escritos. Nesse sentido, ele diz:

Now the cardinal principles of a liberal society - principles such as freedom of expression and association, equality before the law, right of political participation - have to be abstract, since they forego appeal to substantive, culturally specif notions of the good. Yet, if there is to be the mutual trust required for people not merely to regard such principles as correct, but to accept the vulnerability, the dependence on the compliance of others and the subjection to $\mathrm{s}$ tate enforcement, that comes with living in a society governed by them, they must still understand themselves as indeed 'a people; distinct from other peoples and bound together by an antecedent sense of community independent of their acknowledgment of those principles.' But it can involve such circumstantial factors as geography and language, and it will certainly and most importantly include a shared historical experience, centered on the memory of past conflicts, often bloody, and the hard-won realization that the substantive ideals that once defined their political existence s hold now, as abiding objects of reasonable disagreement, cease to have this authoritative function. (Lamore, Charles, 2015, p. 65). 
Assim sendo, na contemporaneidade, os princípios que norteiam a sociedade liberal, tais como os princípios da liberdade de expressão e associação, igualdade perante a lei, direitos de participação política, são abstratos, isto é, não apelam para noções substantivas, específicas, do bem. Portanto, conforme a citação anterior, as pessoas devem entender que um povo é distinto de outros povos. Sendo assim, elas são unidas por um senso anterior de comunidade independente do reconhecimento desses princípios. É nesse sentido que a vida comum não pode ter como paradigma uma definição, culturalmente específica, do bem humano.

Em contrapartida, a vida comum deve envolver fatores circunstanciais como geografia, linguagem e uma experiência histórica compartilhada. Tais aspectos devem levar à constatação de que os ideais substantivos podem ser objetos permanentes de desacordo razoável. Nessa perspectiva, os princípios da associação política são independentes de convicções religiosas, de noções substantivas da boa vida, de ideais éticos relacionados às concepções do bem que defendemos, porquanto não se deve promover alguma idéia particular do bem, mas criar as condições de justiça. Deve-se possibilitar um quadro justo de regras e instituições que seja imparcial em que as pessoas podem perseguir seus vários fins.

Então, Larmore, após tratar da questão do desacordo razoável, em uma perspectiva do liberalismo político, discorre sobre a problemática de como pode-se ter o compromisso para estabelecer um sistema justo de justiça, onde esse não deve ser tratado erroneamente se se supuser que seu objetivo primordial é assegurar uma base para a associação política sobre a qual todas as pessoas razoáveis possam concordar. Deve-se ter respeito igual em relação às pessoas. Nesse sentido, a discórdia razoável é o problema crucial o qual oferece uma solução política. É o fenômeno que deve guiar nosso pensamento político.

Portanto, segundo Larmore, a discórdia razoável, mesmo sendo o problema crucial que oferece uma solução política, seu resultado não repousa em suposições morais. Ele pode considerado correto e não ser compartilhado universalmente. Nesse ponto essencial, o liberalismo político é, freqüentemente, mal entendido (mesmo por alguns de seus proponentes), e, segundo Larmore, uma das suas principais ambições é dissipar a confusão.

Conforme o filósofo, o liberalismo contemporaneo deveria superar as formulações do liberalismo clássico, o qual se baseia em concepções relativas às doutrinas abrangentes. Em contrapartida, Larmore assegura que, entre pessoas razoáveis que discutem sobre o bem e a felicidade humana, é natural que haja desacordo. Mediante esse quadro relativo às perspectivas do liberalismo contemporâneo, Larmore introduz a noção do princípio de igual respeito como preceito básico para a associação política. Em outras palavras, tal norma 
tem como significado o respeito igual para as pessoas e ela tem como função ser um princípio político fundamental que os cidadãos, mesmo que todos estejam com suas visões morais abrangentes e essas sejam controversas, porque sáo individualistas, em submetidos a ele, devem ter motivos para apoiá-lo, assumindo que estão comprometidos em organizar a associação política com base em regras que podem satisfazer o consentimento racional de todos.

Assim, Larmore não pretende afirmar que há regras que possam ter um consentimento racional de todos, mas argumenta que os princípios políticos corretos são aqueles que cidadãos teriam razão para aceitar, se eles estivessem comprometidos, isto é, empenhados a fundar a vida política sobre princípios racionalmente aceitáveis. Dessa forma, o princípio político do igual respeito parece impor, teoricamente, que merecem respeito mesmo aqueles que não se comprometem a fundar uma associação política sobre princípios aceitável para todos (Atzori).

Nessa perspectiva, para o filósofo, os princípios políticos fundamentais não derivam, somente,da razão humana. Isso significa dizer que nenhum conjunto de princípios políticos tem uma acessibilidade universal. Portanto, o liberalismo não é universal. Ele pode ter validade universal, porquanto o princípio de igual respeito, plausivelmente, pode ser considerado correto para todos. Nesse sentido, o respeito aos outros representa a justificativa ética nas instituições democráticas. No entanto, um problema de inadequação pode ser observado no raciocínio de Larmore, ou seja, a circularidade que a sua proposta suscita (Atzori).

Segundo Atzori, a definição do princípio larmoriano implica respeito, mas ele não o justifica,pois Larmore explica o respeito, contudo não demonstra o princípio. Além disso, ele argumenta que o sentido de tal princípio é respeitar até as pessoas que não se comprometem a fundar uma associação política. Sendo assim, o respeito parece ser um princípio inclusivo: o mesmo que Larmore critica nos filósofos que associam liberalismo e individualismo, sublinhando o problema do fato de excluirem alguém. Contudo, tem-se a sensação de que Larmore assume como premissas, na descrição do princípio do respeito igual, aquelas mesmas conclusões que em outros critica, isto é, algumas versões abrangentes do liberalismo contemporâneo que esperam que a adesão aos princípios políticos seja substancial para todos tendo como certo o reconhecimento universalmente compartilhado (Atzori).

Conforme Atzori, no texto Political Liberalism: Its Motivations and Goals é afirmada a diferença entre os liberalismo clássico e o larmoriano, ou seja, consta que o primeiro é excludente porque é fundado no individualismo, enquanto o segundo pratica o tipo certo de exclusão com base no princípio da igualdade de respeito, porquanto, considerando os excluídos como cidadãos, esses teriam um papel a desempenhar na política de associação. Contudo, At- 
zori não acha que isso seja uma diferenciação convincente e acredita que a posição do filósofo parece ter um raciocínio paradoxal, uma vez que ele aponta os dados a partir dos quais se desenvolve o liberalismo e o desacordo razoável em torno dos ideais da boa vida, mas, ao mesmo tempo, parece esperar que a adesão aos princípios políticos seja essencial para todos, tendo como certo o valor do reconhecimento como universalmente compartilhado.

\section{DEFINIÇÃO DE PLURALISMO}

O pluralismo pode ser considerado algo que trata sobre a natureza da moralidade, ou uma afirmação sobre a natureza da auto-realização humana. «Often it presents itself as both» (Larmore, 1994, p. 64). No entanto, para Larmore, as duas posições são logicamente independentes. Moralidade não significa auto-realização ou uma boa vida. Há coisas que ultrapassam a isso, porquanto o fato de algo ser moralmente correto, não nos leva à uma boa vida. No entanto, isso não signica um desprezo à moralidade, pois nada impede que ela possa ser um aspecto importante para a boa vida. Contudo, pode-se, plausivelmente, ser um pluralista sobre moralidade, sem isso ser um aspecto da boa vida ou pode-se ter uma boa vida sem ser um pluralista da moralidade. «Kant, for example, seems to have been a pluralist about happiness, though obviously not about morality» (Larmore, 1994, p.64).

Nessa perspectiva, as mais diversas concepções pluralistas afirmam que várias reivindicações morais que recaem sobre nós, como, também, as formas de auto-realização, não podem ser definidas como algo uno, mas, sim, como múltiplo. É, em outras palavras, uma doutrina sobre as fontes de valor. Sendo assim, o pluralismo moral é a concepção de que nossas convicções morais não advém do princípio consequencialista, isto é, não decorre da tese de que o valor moral de uma ação está nos efeitos por ela produzidos ou provocados, ou seja, nas suas consequências de trazer o melhor para a maioria. Assim, não é enfatizado se a nossa ação maximiza ou não o bem total de todos os afetados.

Em consonância com o exposto anterior:

Similarly, pluralism about the good life is the view that the value we find in different ways of life cannot be illuminatingly explained in terms of their all expressing or promoting a single kind of good, such as pleasure or freedom. (Larmore, 1994, p.64).

Nesse aspecto, é conveniente salientar que existem diferentes formas do bem em relação aos nossos interesses. No entanto, para Larmore, é lamentável que o pluralismo seja, frequentemente, visto como relacionado a uma apreciação dos conflitos entre os nossos valores, onde nem todas as coisas boas podem existir juntas em uma vida individual e nem na sociedade como 
um todo. Para ele, isso não é errado, mas torna-se uma visão equivocada do pluralismo, assim:

Once we consider pluralism as fundamentally a doctrine about the multiple sources of value, we can see that value conflict can have a special significance for the pluralist, not because of its prevalence, but because of its frequent difficulty, and this because of its ultimate explanation (Larmore, 1994, p. 65).

Conforme esse enfoque, os pluralistas terão que admitir que as resoluções de conflito de valor podem gerar desacordo e deverão reconhecer que diversos conflitos entre valores não podem ser, razoavelmente, resolvidos. Assim, «Values may be comparable without being commensurable» (Larmore, 1994, p. 67). E Larmore exemplifica: imaginemos uma situação em que, tendo feito uma promessa a uma pessoa, descobrimos que um amigo precisa do nosso conselho sobre uma decisão importante que ele deve tomar, e que só podemos nos encontrar com ele a tempo se não mantivermos a promessa ao outro indivíduo. Larmore, então, afirma que, primeiro, deveríamos ajudar nosso amigo, porquanto a amizade deve ter precedência em relação ao dever.

Sendo assim, os dois valores são comparáveis e não existe um denominador comum de valor em relação á comensurabilidade dos mesmos. Os valores não são mais ou menos valiosos conforme promovem ou expressam algo em maior ou menor grau. "It is in this sense that I mean that the two values, though comparable, need not be commensurable». (Larmore, 1994,p.68).

Entretanto, Larmore, seguindo Herder, ${ }^{1}$ afirma que não acredita que todo valor moral deriva da auto-legislação racional de agentes autônomos. Se assim não for, por causa das outras formas de bem incompatíveis com ela, como, por exemplo, a lealdade familiar, há custos morais nesse tipo de ética.

The pluralist's most common strategy in the face of worries about choices between incommensurable values is to appeal to practical wisdom - the faculty described by Aristotle - a faculty of judgment that the wise and virtuous person has, which enables him to see the right answer. Practical wisdom is not just a question of being able to see and collate the facts, it goes beyond that in some way-the wise person will see things that only a wise person could see. So plural values can be compared in that a wise person will 'just see' that one course of action rather than another is to be taken. This strategy is used (explicitly or implicitly) by McDowell (1979), Nagel (1979), Larmore (1987), Skorupski (1996), Anderson (1993 and 1997) Wiggins (1997 and 1998), Chappell (1998), Swanton (2003). (Mason 2018)

1 Herder, Briefe zur Beforderwig der Humanitat (1793-97), Sechste Sammlung. 
Assim sendo, não podemos, em boa consciência, considerar nosso próprio universalismo moral como superior as muitas diferentes moralidades. Certamente, nós podemos, razoavelmente, acreditar que alguns desses bens são mais importantes do que outros. Dessa forma:

Perfectionist liberalism is defined by Larmore, who initiated this debate, as a family of views that base political principles on 'ideals claiming to shape our overall conception of the good life, and not just our role as citizens'; elsewhere he says that these views involve controversial ideals of the good life, or views about 'the ultimate nature of the human good.'As I define perfectionist liberalism, following Larmore, it is a species of a genus of liberal views that might be called 'comprehensive liberalisms', liberalisms that base political principles on some comprehensive doctrine about human life that covers not only the political domain but also the domain of human conduct generally. (Nussbaum, 2011, p. $10)$.

Conforme a citação anterior, há um tipo de liberalismo, que não é o caso da teoria larmoriana, que pode ser definido como abrangente, porquanto baseiam os princípios políticos em alguma doutrina sobre a vida humana que abrange o domínio da conduta humana em geral.

\section{LIBERALISMO E PLURALISMO}

Para Larmore, a principal ambição no liberalismo é encontrar a associação de princípios políticos, expressando certos valores morais fundamentais que, tanto quanto possível, pessoas razoáveis podem aceitar, apesar das diferentes visões sobre o bem e sobre a verdade religiosa que as divide. No entanto, não devemos esperar que os princípios do liberalismo se mantenham acima das mais diversas concepções de vida, porquanto o pluralismo é uma doutrina muito controversa. Contudo:

What is the relationship between moral pluralism and the political philosophy of liberalism? According to Charles Larmore, moral pluralism cannot provide a foundation for liberal politics. The reason is that the aim of liberalism is to find principles that all reasonable people would accept, regardless of their particular views concerning the good. Moral pluralism is far too controversial to be among those principles; individuals may readily be regarded as reasonable, even though they reject the pluralist account of our moral universe. (Galston, 1999, p. 885)

Assim, conforme Galston, a posição de Larmore está muito em voga, pois ela combina o problema prático de chegar a um consenso com o teórico, isto é, com a tarefa de alcançar a justificação. Em relação a isso, Galston, então, pede que suponhamos que o pluralismo seja a mais adequada forma para dar conta da moralidade e que o liberalismo é semelhante em relação á teoria política. 
Seria estranho se eles não fossem coerentes entre si. O pluralismo poderia ser relacionado com os outros modos de política do que liberal, e o liberalismo pode ter espaço para visões morais além do pluralismo. No entanto, o pluralismo moral não deve afirmar algo que o liberalismo nega, ou vice-versa, pois embora a razoabilidade e a verdade sejam diferentes, isso não é argumento contra a relevância da verdade para justificação. Nessses termos, para Galston, a tese de Larmore é sustentável apenas quando não exista a lacuna entre o que é razoável e o que é verdade. No entanto, conforme Larmore, é mais provável que se valorize o pluralismo como uma verdade contestada e um objeto de desacordo razoável do que para ser um princípio orientador para o liberalismo.

Sendo assim, para Larmore, é importante admitir a diferença entre o pluralismo e a discordância razoável, porquanto este último tem uma relação com a base política do liberalismo, enquanto o pluralismo não possui. O problema, de acordo com Larmore, é que muitos teóricos confundem o fato do desacordo razoável com a noção de pluralismo. Nessa perspectiva, Larmore define o pluralismo como a convicção de que, no final, o bem humano não é um, mas muitos, suas diferentes formas são irredutíveis a qualquer base única como, por exemplo, ao prazer.

O pluralismo difere do fato do desacordo razoável, pois o pluralismo é um acordo sobre o valor independente e igual de diferentes ideais. Nesse sentido, a expectativa de desacordo razoável é, na verdade, uma visão mais perturbadora do que o pluralismo. Em outras palavras, isso significa que o reconhecimento de que, em questões de suma importância, a razão não é provável para unir algo, mas tende a afastá-lo. Assim:

Bernard Williams (1981), Charles Larmore (1987), John Kekes (1993), Michael Stocker (1990 and 1997), David Wiggins (1997) have all argued that there are at least some genuinely irresolvable conflicts between values, and that to expect a rational resolution is a mistake. (Mason 2018)

Nessa perspectiva, segundo Larmore, uma concepção de liberalismo, que tem o pluralismo como preocupação fundamental, é uma doutrina muito controversa, porquanto ao confundir o fato de desacordo razoável com a noção de pluralismo, os teóricos falham em abordar a realidade do conflito da moral moderna e impedem a possibilidade de desenvolver uma concepção de justiça que conceda o grau apropriado de respeito a todos os indivíduos.

Portanto, o liberalismo não deve ter como base uma aceitação do pluralismo, mas isso não é porque o pluralismo é uma forma de erro do qual o liberalismo faria melhor para se libertar. Pelo contrário, o pluralismo é algo que deveríamos aceitar. No entanto, isso é uma verdade sem relevância para o liberalismo, e, de fato, é uma doutrina em cuja verdade ou falsidade o libe- 
ralismo não precisa se pronunciar. A associação equivocada entre liberalismo e pluralismo ocorre porque o pluralismo não foi adequadamente distinguido de uma ideia que se encontra no cerne da autocompreensão do pensamento liberal. (Young, 2002, 53).

Larmore acredita que a associação do pluralismo com o liberalismo é mal concebida, porquanto a concepção do pluralismo é moderna. Ela pertence a uma visão de mundo desencantada que se vê como tendo abandonado o conforto de encontrar na harmonia do cosmos ou na ordem providencial de Deus do mundo a última fonte de valor. «Larmore has been the principal champion of the concept of political liberalism, producing a noteworthy quantity of analysis directly devoted to developing a viable conception of political liberalism.» (Young, 2012, p.68). A alegação de Larmore é que o conceito de desacordo razoável e o ideal correspondente de tolerância não fazem sentido sob uma visão monista da boa vida.

\section{CONSIDERAÇÕES FINAIS}

Larmore vê o liberalismo como uma doutrina política neutra frente aos conflitos referentes à boa vida. Assim sendo, o liberalismo é autônomo em relação às concepções abrangentes, porém não o é em relação à moralidade, porquanto ele considera o princípio do igual respeito a base moral do liberalismo.Nessa perspectiva, os julgamentos sempre produzirão discordância entre pessoas razoáveis, racionais e livres. Porém isso sempre produzirá desacordos razoáveis. Portanto deve-se justificar os princípios políticos de uma forma razoável.

Entretanto, Charles Larmore afirma que o problema do desacordo razoável não é algo como uma simples discordância, mas alguma coisa em que as pessoas razoáveis, exercendo boa fé, tendem a chegar, mesmo com opiniões contrárias. Presumivelmente, se duas pessoas discordarem, elas podem chegar a um acordo. O desacordo razoável é uma condição temporária. Isso significa dizer que as pessoas podem recuar e retratar suas visões anteriores.

Contudo, Larmore afirma que as formas de lidar com desacordos razoáveis são confusas. O desacordo pode persistir quando o assunto é de grande complexidade, ou seja, quando o tema em questão tem a possibilidade de ser interpretado de forma variada. Nesse caso, pode-se pressupor que a razão contemple e dissolva os conflitos. Assim sendo, a discordância razoável pode, plausivelmente, não fazer sentido. No entanto, a discordância será razoável quando as visões razoáveis são justificadas, embora não precisam ser verdadeiras, elas podem ter razões para ser aceitas. É por isso que o desacordo é razoável, porquanto cada lado mantêm posições justificadas, onde os diferentes lados julgam que há uma resposta correta à questão que divide-os. Então, ter uma razão, presumidamente, significa que ela, realmente, exista, embora tal 
razão possa existir, somente, em sua própria perspectiva. A solução, porém, é a questão da justificação dos pontos de vistas razoáveis. Eles são justificados, embora não precisem ser todos verdadeiros.

Pode-se, plausivelmente, afirmar que a teoria de Larmore tem uma visão contextualista-pragmatista da justificação. Isso significa que a visão de alguém é justificada se suas premissas, também, sejam justificadas. Assim, precisamos de justificativas apenas quando surge algum conflito existente em um contexto de crenças dadas que não precisam ser justificadas em si mesmas, onde, é interessante considerar que os nossos pontos de vista não são melhores apoiados pela experiência e reflexão do que as de outras pessoas. Assim sendo, o desacordo é inevitável, porquanto diferentes concepções da boa vida envolvem diferentes propósitos e significados.

Nesse sentido, Larmore não considera nosso próprio universalismo moral como superior, por exemplo, ao tribal. Muitos vão questionar sobre como os valores incomensuráveis podem ser, ainda, comparáveis. Se não apelarem para um denominador comum, então, como os valores podem ser comparados uns contra os outros? Larmore admite que não tem resposta satisfatória a esta pergunta, embora ele acha que os relatos recentes de percepção moral podem ser úteis.

No entanto, uma incapacidade de resolver este problema não é tão prejudicial quanto possa parecer. As vezes, podemos legitimamente afirmar saber algo, sem saber como é que nós sabemos disso.

Segundo Charles Larmore, somente, compreendendo o fato do desacordo razoável, pode-se vislumbrar uma concepção de justiça que tem a possibilidade de assegurar a estabilidade necessária para estabelecer e sustentar um Estado liberal. No entanto, o desacordo razoável não pode ser definido como pluralismo razoável. Larmore define o pluralismo como algo que no final o bem humano não é um, mas muitos, suas diferentes formas são irredutíveis a qualquer base única.

Para Larmore, a expectativa de desacordo razoável é, na verdade, uma visão mais inquietante que o pluralismo. É o reconhecimento de que, em assuntos importantes, a razão não é susceptível de unir, mas tendem a nos separar. As concepções de justiça animadas pela noção de pluralismo só podem agravar o problema de desacordo razoável. Ao confundir o fato de razoável desacordo com a noção de pluralismo, os teóricos não conseguem abordar a realidade da moral moderna de forma eficaz e, ao fazê-lo, excluem a possibilidade de conceder o grau de respeito adequado a todos os indivíduos. Nessa perspectiva, Larmore afirma que sua concepção de justiça é política e moral que baseia-se em deveres morais fundamentais que temos um ao outro e expressa um compromisso moral para encontrar termos de associação política que pode ser objeto de desacordo razoável. 


\section{REFERENCIAS BIBLIOGRÁFICAS}

ATZORI, Claudia, «La proposta liberal di Charles Larmore nel dibattito post rawlsiano». Disponible en: https://www.cosmopolisonline.it/articolo.php?numero $=$ XIII12016\&id $=9$

FANTON, Marcos (2015), O princípio do respeito igual como a melhor resposta às experiências da modernidade: a filosofia política de Charles Larmore. São Paulo: Cadernos de Ética e Filosofia Política. Número 27.

GALSTON, William A. (1999), «Expressive Liberty, Moral Pluralism, Political Pluralism: Three Sources of Liberal Theory», William. \& Mary Law Review 40, p. 869. Disponible en http://scholarship.law.wm.edu/wmlr/vol40/iss3/9.

LARMORE, C. (1987), Patterns of Moral Complexity. New York: Cambridge University Press.

LARMORE, Charles. (1994), Pluralism and Reasonable Disagreement. New York: Social Philosophy and Policy.

LARMORE, C. (1996), Morals of Modernity. New York: Cambridge University Press.

LARMORE, C. (1999), «The Moral Basis of Political Liberalism», Journal of Philosophy.

NUSSBAUM, Martha C. (2011), «Perfectionist Liberalism and Political Liberalism», Philosophy \& Public Affairs 39, no. 1.

MASON, Elinor. (2018), «Value Pluralism», The Stanford Encyclopedia of Philosophy. https://plato.stanford.edu/archives/spr2018/entries/value-pluralism

YOUNG, S. (2002), «Illusions of difference? Larmore's political liberalism», Minerva. An Internet Journal of Philosophy, pp. 68-102.

ELNORA GONDIM es professora de Filosofia na graduação e no mestrado profissional da Filosofia na Universidade Federal do Piauí.

Líneas de investigación:

John Rawls, razón pública, educación política

Publicaciones recientes:

(2020). «John Rawls: a questão da verdade e da objetividade», en Discussões Filosóficas: algumas abordagens. 1ed. Teresina: Entre trópicos, pp. 89-100.

(2019). "Rawls e a questão da religião e da razão pública». Horizonte. Revista de Estudios de Teología e Ciências da Religião (online), v. 17, pp. 757-774, 2019.

Correo electrónico: elnoragondim@yahoo.com.br 
